\title{
Paradoxical air embolism following central venous catheter removal
}

\author{
Hiba Khan, Afzal Zaidi
}

Department of Cardiothoracic Surgery, Abertawe Bro Morgannwg University Health Board, Swansea, UK

\section{Correspondence to} Dr Hiba Khan, khanh1@cardiff.ac.uk
To cite: Khan $\mathrm{H}$, Zaidi A. BMJ Case Rep Published online: [please include Day Month Year] doi:10.1136/ bcr-2013-200630

\section{SUMMARY}

Central venous catheters are commonly used in the management of critically ill patients. This case report described a rare but potentially fatal complication of central venous catheter use. A 52-year-old man underwent mechanical aortic valve replacement for infective endocarditis. On day 8 postoperatively he accidentally removed his catheter and collapsed with symptoms and signs suggestive of a cerebral air embolism. A transthoracic echocardiogram showed air bubbles in both the right and left ventricles of the heart confirming the presence of a paradoxical air embolism.

\section{BACKGROUND}

Central venous catheters (CVCs) are commonly used in the management of critically ill patients. It is estimated that over 200000 CVCs are inserted annually in the National Health Service. They provide a means for haemodynamic monitoring and intravenous access for administration of medications, nutrition and haemodialysis. However, use of CVCs is not without its risks. Common complications include infection, bleeding, pneumothorax and thromboembolic events. Air embolism is a rare but serious complication of CVC use.

\section{CASE PRESENTATION}

A 52-year-old man presented to the hospital with fever and polyarthritis. He had no significant medical history. He was found to have raised inflammatory markers, and three separate blood cultures grew a coagulase-negative Staphylococcus.

A transthoracic echocardiogram showed significant aortic regurgitation, with a mobile mass attached to the aortic valve. Infective endocarditis was suspected and the patient was treated with a combination of vancomycin, gentamicin and meropenem. A transoesophageal echocardiogram (TOE) confirmed there was an abnormal tricuspid aortic valve, with a prolapse of a small segment of the non-coronary cusp and the appearance of early aortic root abscess formation on the posterior wall of the aorta.

After 3 weeks of antibiotic therapy, the patient underwent a mechanical aortic valve replacement and debridement of the aortic root abscess. Prior to the surgery a triple lumen CVC was inserted into the right internal jugular vein for perioperative haemodynamic monitoring, it was secured using 2-0 Mersilk sutures and dressed with a Tegaderm. Carbon dioxide insufflation of the pericardial cavity was used during the surgery, and thorough de-airing manoeuvers were performed before removing the cross clamp. Adequacy of de-airing was confirmed on intraoperative TOE. The patient made a good postoperative recovery. He was extubated and moved on to the surgical ward. His CVC remained in situ so he could be continued on triple antibiotic therapy. He was also started on warfarin.

On day 8 postsurgery, the patient caught his CVC while shaving and partially removed it. He was standing upright when he noticed the blood and called for assistance. He was found semiconscious, slumped on the floor. By this time his CVC was entirely out. The patient was maintaining his airway, but his oxygen saturation had dropped to $70 \%$ on air, his respiratory rate was 30 breaths per minute. He had a good cardiac output and was maintaining his blood pressure at $150 / 60 \mathrm{mmHg}$. His heart rate was 156 beats per minute and his ECG showed signs of right heart strain. His Glasgow Coma Scale was 7/15. There was no evidence of head injury. On the day of this event his INR had been 3.7. Pressure was applied to the catheter site and it was covered with gauze and an airtight dressing. The patient was put in a left lateral head down position at which point an abrupt and significant improvement in Glasgow Coma Scale was noticed, rising from $7 / 15$ to $14 / 15$, although he remained agitated and confused. He was put on $100 \%$ oxygen, intubated and transferred to cardiac intensive care.

\section{INVESTIGATIONS}

A TOE performed at his bedside found air bubbles in the right and left ventricles, suggesting paradoxical air embolism (figure 1). No septal defects were identified. Unfortunately the patient was not stable enough at this time to undergo a contrast-enhanced echocardiogram.

CT scan of the head was normal and CT pulmonary angiogram found no evidence of pulmonary embolism.

\section{DIFFERENTIAL DIAGNOSIS}

Cerebral air embolism.

\section{TREATMENT}

The patient was ventilated for $24 \mathrm{~h}$ before being successfully extubated the following day. He had no residual neurological deficit and made a good recovery.

\section{OUTCOME AND FOLLOW-UP}

The patient was discharged after completing his course of intravenous antibiotics. He has been seen at 3 and 6 months in clinic and has no residual 


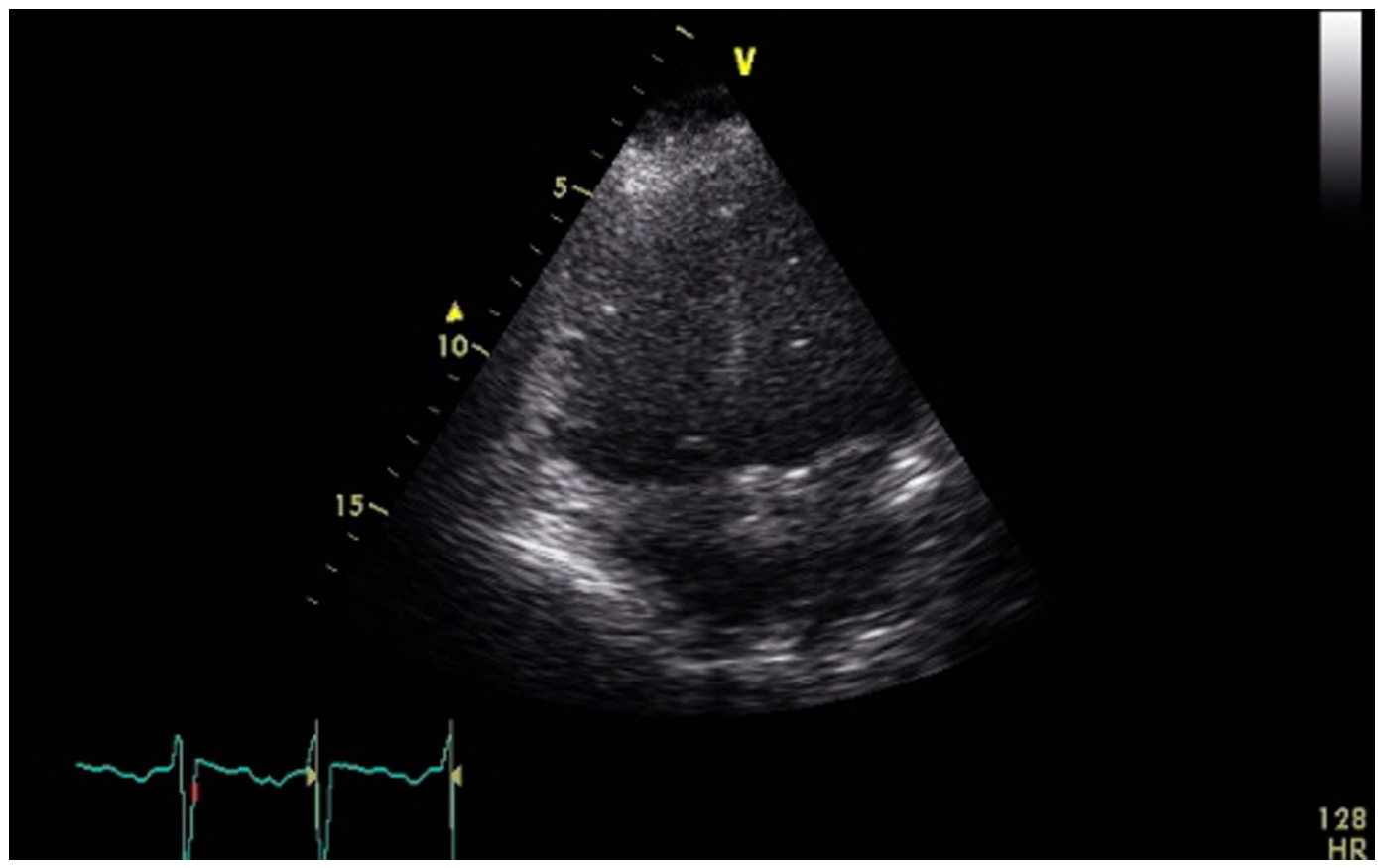

Figure 1 Transthoracic echocardiogram demonstration of air bubbles in the right and left ventricles of the heart.

neurological defect. He is doing well and is due to be seen again in 1 year.

\section{DISCUSSION}

Air embolism occurs when an open channel exists between the central circulation and the outside environment with a pressure gradient that allows air entry into the circulation. This pressure gradient is greater with the patient in an upright position, during inspiration and in hypovolemic states where the central venous pressure is low. In the case discussed here the CVC had been in situ for over a week at the time of removal which meant the tract was well formed. The patient was also in an upright position at the time of removal. ${ }^{1}$

If air enters the venous circulation, it passes through the right side of the heart and into the pulmonary arteries. Small air bubbles are absorbed by the circulation and have little consequence. The majority of patients will therefore remain asymptomatic or develop minor respiratory symptoms only. ${ }^{2}$ Moderate sized air bubbles, however, may cause pulmonary vascular damage leading to pulmonary hypertension and pulmonary oedema. ${ }^{3}$

Larger volumes of air cannot be absorbed and may pass through the pulmonary circulation across arteriovenous shunts and enter the left side of the heart. Larger bolus can also cause right ventricular air lock, which can lead to pulmonary failure and death. ${ }^{4}$ In addition paradoxical emboli may enter the arterial circulation through a ventricular septal defect or an atrial septal defect such as a patent foramen ovale (PFO). It is suggested that the foramen ovale remains patent in 30\% of patients with otherwise normal cardiac anatomy. ${ }^{5}$

In the case discussed here the transthoracic echocardiogram confirmed the presence of air in both the right and left ventricles. There was no suggestion of septal defects on this echocardiogram or on the preoperative TOE. The entry of air into the left ventricle, therefore, either occurred through the pulmonary circulation or through a temporarily functioning PFO. If a large volume of air entered the pulmonary arteries it could have caused an air-lock leading to pulmonary hypertension and right heart strain. This increased pressure can temporarily open a
PFO and allow paradoxical air embolism. If the airlock is then overcome, the pressure in the right ventricle will decrease and allow the PFO to reseal. Once in the arterial circulation, the air emboli can travel to any organ in the body and have devastating consequences such as myocardial infarction and stroke.

A high index of suspicion is needed to diagnose cerebral air embolism. A literature review of 26 patients found that patients with cerebral air embolism either presented with encephalopathic features or with focal cerebral lesions resulting in haemiparesis or haemianopia. Early CT indicated air bubbles in 75\% of the patients they reviewed. ${ }^{6}$ In this patient's case, air was confirmed in the left ventricle. His CT of head was normal, but was performed $6 \mathrm{~h}$ after the onset of symptoms by which time the air bubbles may have dissipated. Given his sudden drop in Glasgow Coma Scale and on-going confusion cerebral air embolism is a likely explanation.

The initial treatment of air embolism is to prevent further air entering the circulation. The entry point should be sealed with an airtight dressing. The patient should be placed in Trendelenburg's position with a left lateral head down tilt to prevent the movement of air into the right ventricular outflow tract. Also100\% oxygen should be administered to encourage resorption from the vasculature. Occasionally aspiration of air from the right ventricle is possible. ${ }^{7}$ Once stabilised, hyperbaric oxygen therapy can be used to decrease the size and effects of the emboli. ${ }^{8}$

Prevention of air embolism is paramount. All staff inserting and removing CVCs should be trained and competent in doing so. Both insertion and removal should be carried out in a supine position. Once a catheter is inserted, it should be secured with sutures and dressings to prevent its accidental removal. If patients are mobilising with CVCs in place, then they should be taped down as far as possible to prevent the lines getting caught and pulled. On removal, the tract should be coved with an airtight dressing. Staff awareness of air embolism as a complication of CVCs is essential in both the prevention and early diagnosis of this rare but potentially fatal phenomenon. 


\section{Learning points}

- To provide safe care of patients with central venous catheter, staff need to be aware of potential complications.

- With the implementation of simple risk reduction strategies serious complications such as air embolism can be prevented.

- Early identification of patients with symptoms of air embolism and prompt resuscitation and treatment may reduce subsequent morbidity.

Contributors HK and AZ have drafted and revised the manuscript.

Competing interests None.

Patient consent Obtained.
Provenance and peer review Not commissioned; externally peer reviewed.

\section{REFERENCES}

1 Wu YC, Liu HP, Liu YH, et al. Paradoxical cerebral air embolism after removal of a central venous catheter: case report, 2000. Chang Gung Med J 2000;23:706-10.

2 Vesely T. Air embolism during insertion of central venous catheters. J Vasc Interv Radiol 2001;12:1291-5.

3 Fitchet A, Fitzpatrick AP. Cerebral venous air embolism causing pulmonary edema mimicking left ventricular failure. BMJ 1998;16:604-6.

4 Muth CM, Shank ES. Primary care: gas embolism. N Eng J Med 2000;342:476-82.

5 Love BA. Pediatric patent foramen ovale atrial septal defects. Medscape 2012.

6 Heckmann JG, Lang CJ, Kindler K, et al. Neurologic manifestations of cerebral air embolism as a complication of central venous catheterization. Anesth Analg 1992;75:226-31.

7 Shaikh N, Ummunisa F. Acute management of vascular air embolism. J Emerg Trauma Shock 2009;2:180-5.

8 Feil M. Reducing risk of air embolism associated with central venous access devices. Pennsylvania Patient Safety Advisory 2012;9:58-64.

Copyright 2013 BMJ Publishing Group. All rights reserved. For permission to reuse any of this content visit

http://group.bmj.com/group/rights-licensing/permissions.

BMJ Case Report Fellows may re-use this article for personal use and teaching without any further permission.

Become a Fellow of BMJ Case Reports today and you can:

- Submit as many cases as you like

- Enjoy fast sympathetic peer review and rapid publication of accepted articles

- Access all the published articles

- Re-use any of the published material for personal use and teaching without further permission

For information on Institutional Fellowships contact consortiasales@bmjgroup.com

Visit casereports.bmj.com for more articles like this and to become a Fellow 